Khairullah Anuar, $\mathrm{MBChB}^{1}$

Marina Mat Baki, MD, MSurg (ORL-HNS)'

Abdullah Sani, MD, MSurg (ORL-HNS)'

Primuharsa Putra Sabir Husin Athar, MD, MSurg

$(\mathrm{ORL}-\mathrm{HNS})^{2}$

'Department of Otorhinolaryngology

Head and Neck Surgery

Universiti Kebangsaan Malaysia Medical Center

Cheras, Kuala Lumpur, Malaysia

${ }^{2}$ Ear, Nose \& Throat-Head \& Neck Consultant Clinic KPJ Seremban Specialist Hospital,

Seremban, Negeri Sembilan, Malaysia
Correspondence: Dr. Primuharsa Putra Sabir Husin Athar Consultant ENT-Head \& Neck Surgeon

KPJ Seremban Specialist Hospital

Jalan Toman 1, Kemayan Square, 70200

Seremban, Negeri Sembilan

Malaysia

Fax : (606) 7653406

E-mail : putrani@yahoo.co.uk

The authors declared that this represents original material that is not being considered for publication or has not been published or accepted for publication elsewhere, in full or in part, in print or electronic media; that the manuscript has been read and approved by all the authors, that the requirements for authorship have been met by each author, and that each author believes that the manuscript represents honest work.

Disclosures: The authors signed disclosures that there are no financial or other (including personal) relationships, intellectual passion, political or religious beliefs, and institutional affiliations that might lead to a conflict of interest.

Presented at the 30th MSO-HNS Annual General Meeting \& Second Malaysian International Otorhinolaryngology Head \& Neck Conference, Nexus Resort \& Spa, Karambunai, Kota Kinabalu, Sabah, Malaysia, 3-5 June 2010.

\section{Hoarseness Due to Cardiovascular Disease: Two Cases of Cardiovocal Syndrome}

\author{
ABSTRACT \\ Objective: To report two cases of cardiovocal syndrome (or Ortner's syndrome) due to \\ cardiovascular disease.
}

\section{Methods:}

\author{
Design: Case report \\ Setting: Tertiary University Hospital \\ Subjects: Two
}

Results: Two patients with Cardiovocal syndrome, one due to an aortic saccular aneurysm and the other due to severe mitral stenosis underwent surgery to correct the underlying cardiovascular disease. Post-operatively, the hoarseness resolved completely in the patient with mitral stenosis but persisted in the patient with aortic saccular aneurysm.

Conclusion: Cardivascular disease should be considered as a differential diagnosis in a patient with hoarseness. A high index of suspicion is needed to make an early diagnosis which can lead to surgical correction of the potentially life-threatening, underlying cardiovascular disease.

Keywords: cardiovocal hoarseness, Ortner's syndrome, cardiovascular disease, aortic aneurysm, mitral stenosis

Hoarseness caused by damage to the recurrent laryngeal nerve as a result of cardiovascular causes is known as cardiovocal syndrome (or Ortner's syndrome). This rare syndrome was first described in 1897 by Nobert Ortner, an Austrian physician. 'Although Ortner originally described this syndrome in association with mitral stenosis, it is now recognized as a complication of a number of cardiovascular diseases. Cardiovocal syndrome remains rare but occurs at a higher prevalence (0.6-5\%) in patients with mitral stenosis than in the general population. ${ }^{2}$ Cardiovocal syndrome usually resolves if detected early and the underlying cardiovascular etiology is corrected or treated. We report two cases of the syndrome: one is due to an aortic saccular aneurysm and the other due to severe mitral stenosis.

\section{Case 1}

\section{CASE REPORTS}

A 51-year-old Malay male with a history of end stage renal failure secondary to hypertension was admitted to the hospital for aspiration pneumonia. He had been having bouts of cough for four months associated with progressive hoarseness and worsening of choking and coughing on swallowing liquid. On examination, the patient was comfortable at rest. He had no stridor or respiratory distress but had hoarseness. There was no palpable cervical lymphadenopathy. 


\section{CASE REPORTS}

A rigid indirect $70^{\circ}$-laryngoscopy showed left vocal cord palsy with a phonatory gap. No other lesions were seen in the larynx. Bibasilar crepitations were present over the lungs. A CT scan showed a saccular aneurysm just distal to the origin of the left subclavian artery, pushing the trachea to the right. This aneurysm measured $6.74 \mathrm{~cm}$ in diameter. (Figure1) Flexible endoscopic evaluation of swallowing (FEES) showed a delayed swallowing response triggered at the base of tongue. Laryngeal sensation and pharyngeal contraction were also reduced. The thickened liquids given during the FEES were cleared only after a third swallow. The patient was placed on an oral diet with thickened liquids and advised on techniques for safer swallowing. The clinical diagnosis was left unilateral vocal cord palsy secondary to saccular aneurysm. He was referred to cardiothoracic surgery and underwent an elective aneurysmectomy. Post-operatively, the patient was well but the hoarseness persisted. He was advised to follow-up six months later but was not seen again.

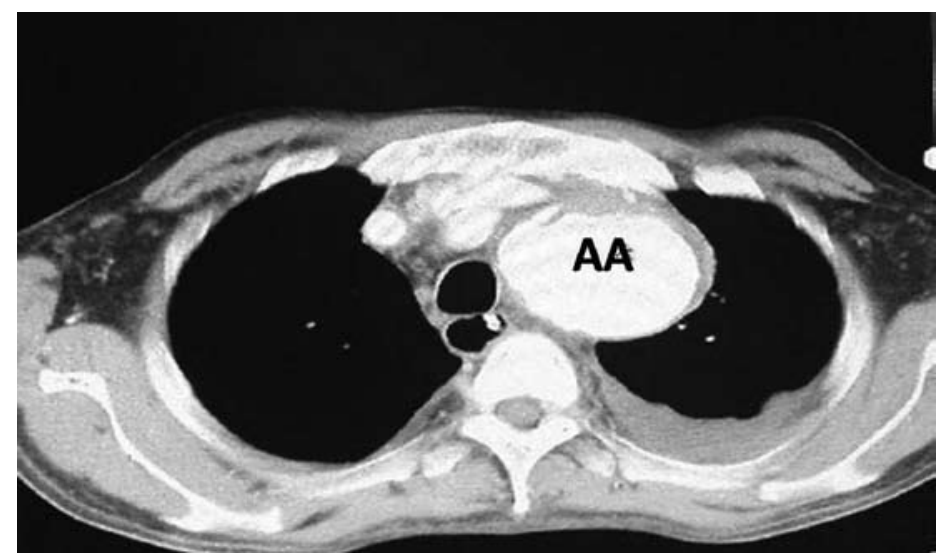

Figure 1. Transverse computed tomographic scan of the chest showing aortic aneurysm (AA).

\section{Case 2}

A 44-year-old Malay man presented with a 4-day history of hoarseness, shortness of breath and symptoms of mild orthopnea and aspiration. He denied any history of dysphagia, chronic cough, sore throat, chest pain, palpitations or decreased tolerance of exertion. He had no history of hypertension, diabetes, asthma or recurrent fever with sore throat during childhood.

On examination, the patient appeared well. His blood pressure was $100 / 60 \mathrm{~mm} \mathrm{Hg}$ and his pulse was irregular with a rate of $78 / \mathrm{min}$. He had no peripheral edema, cyanosis or clubbing. The head and neck examinations were normal. Cardiovascular examination revealed no displacement of the apex beat. On auscultation, the first heart sound was loud and a grade 3/6 long rumbling diastolic murmur was heard in the mitral area. Bilateral basal crepitations were heard over the lungs. $A$ rigid indirect laryngoscopy using a $70^{\circ}$-laryngoscope showed left vocal cord palsy with the cord in the paramedian position and a phonatory gap.
The patient's hemoglobin was $14 / 1 \mathrm{~g} / \mathrm{dL}$, total white cell count $12.010^{3} / \mu \mathrm{L}$ and platelet count $432,103 / \mu \mathrm{L}$. Sodium was $136 \mathrm{mmol} / \mathrm{L}$, potassium $4.4 \mathrm{mmol} / \mathrm{L}$, blood urea was $8.6 \mathrm{mmol} / \mathrm{L}$ and serum creatinine $88 \mu \mathrm{mol} / \mathrm{L}$. An electrocardiogram showed atrial fibrillation at a rate of $80 / \mathrm{min}$. A chest radiograph showed mild cardiac enlargement without pleural effusion. A thoracic computed tomography (CT) scan showed left atrial enlargement with prominent pulmonary veins. Echocardiography showed dilation of the left atrium and a thickened mitral valve. (Figure 2) The mitral valve area was $0.6 \mathrm{~cm}^{2}$ based on the calculation from pressure half-time. Left ventricular systolic function was good with an ejection fraction of $70 \%$. A coronary angiogram showed normal coronary arteries. A diagnosis of severe mitral stenosis with heart failure was made. Pre-operatively the patient was stabilized and referred for dental clearance. He then underwent surgery for mitral and aortic valve replacement. Post-operatively, he recovered uneventfully. His hoarseness resolved completely after three months of speech therapy and repeat rigid laryngoscopy showed complete recovery of left vocal cord function.

\section{DISCUSSION}

Cardiovocal syndrome is a clinical entity manifested by hoarseness caused by an impaired ability of the left recurrent laryngeal nerve to transmit impulses to laryngeal musculature because of stretching or impingement of the nerve from disease-induced changes in cardiac or great vessel anatomy. Hoarseness due to paralysis of the left recurrent laryngeal nerve caused by a dilated left atrium in mitral stenosis as discussed by Ortner is a subject of controversy. Different authors have cited different mechanisms for the syndrome and a variety of cardiac problems can lead to paralysis of the left recurrent laryngeal nerve. These include thoracic aortic aneurysms, patent ductus arteriosus, primary pulmonary hypertension, atrial and ventricular septal defects, Eisenmenger's syndrome and recurrent pulmonary embolism. ${ }^{3}$

To understand how cardiovocal syndrome arises, one has to consider the anatomical position of the recurrent laryngeal nerve and the left atrium. On the right, the recurrent laryngeal nerve crosses around the first part of the subclavian artery and travels in the groove between the trachea and esophagus. On the left, the vagus nerve gives off the recurrent laryngeal nerve at the aortic arch. This nerve hooks around the lateral aspect of the ligamentum arteriosum, passes up the right side of the aortic arch and ascends in the groove between the esophagus and trachea. The lengthy course of the recurrent laryngeal nerve in the thoracic cavity especially around the aortic arch makes it vulnerable to compression, traction and erosion by enlarged or displaced cardiac chambers, dilated pulmonary arteries and a dilated aorta. ${ }^{4,5}$ Contrary to its name, the left atrium does not lie on the left side but forms the most posterior chamber of the heart. It is closely related to the esophagus, spine, left recurrent laryngeal nerve, pulmonary vessels, lung parenchyma and bronchi. Therefore, when the left atrium enlarges, it 

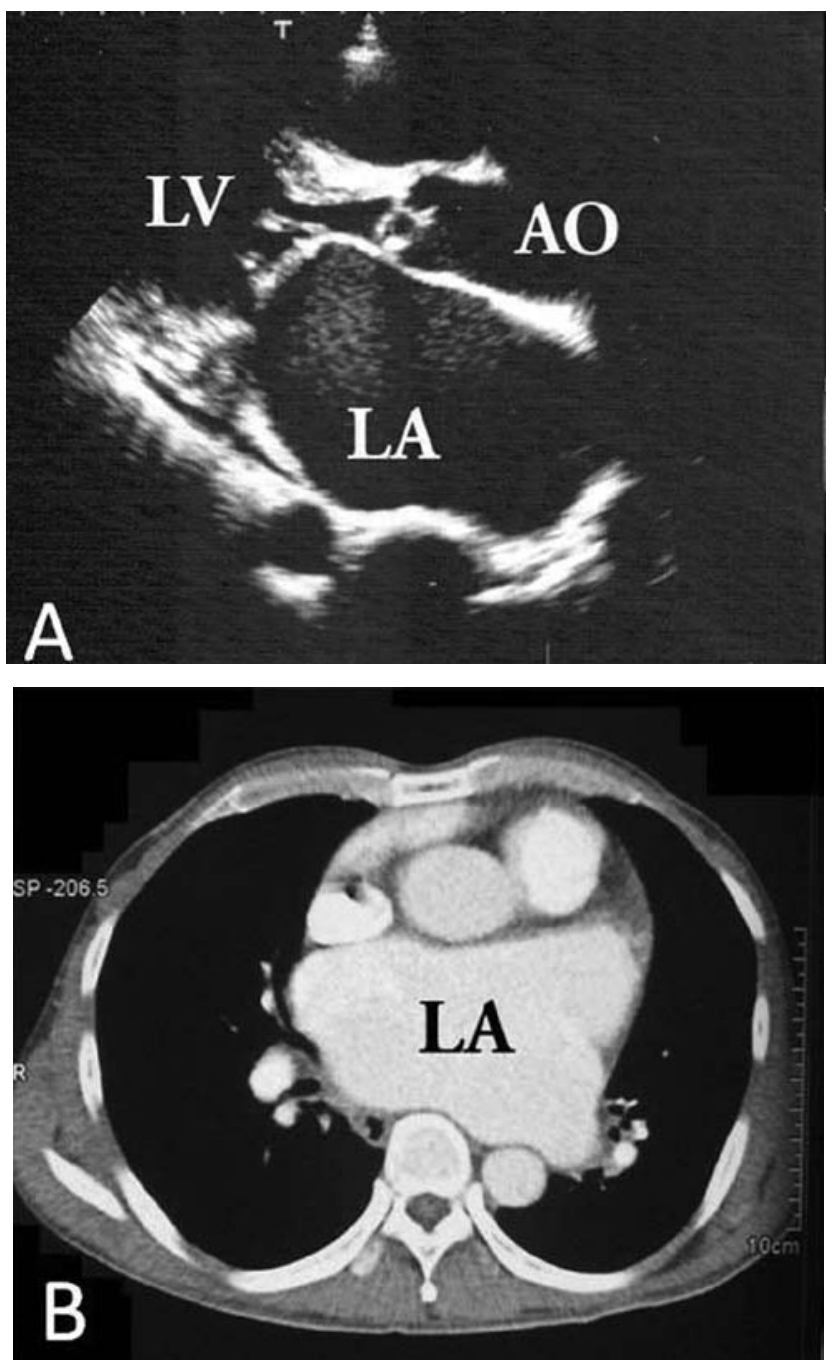

Figure 2. (A) Transthoracic echocardiography showing a huge left atrium. LA indicates left atrium; LV, left ventricle; and AO, aorta. (B) Transverse computed tomographic scan of the chest showing left atrial enlargement.

causes complications by compressing these adjacent structures. ${ }^{6}$

Most authors believe that pressure in the pulmonary artery causes the nerve compression.

However, the dilated left atrium found in mitral stenosis or patent ductus arteriosus may compress the vagus nerve. ${ }^{7}$ Cardiovascular pathology is a rare cause of left vocal cord palsy. The incidence of mitral stenosis causing this syndrome ranges from 0.6 to $5 \% .^{8}$ De Bakey et al. reported that $8.6 \%$ of their patients complained of hoarseness caused by stretching or compression of left recurrent laryngeal nerve, ${ }^{9}$ Leonetti reported that 8 of 168 patients (4.8\%) with thoracic aortic aneurysms (TAA) presented with hoarseness and all of these had type I aneurysms (de Bakey classification) involving the ascending root and aortic arch. ${ }^{10}$

The treatment of and prognosis for this syndrome depends on the possibilities of managing the underlying cause. If detected early, the syndrome is usually reversible. Both of our patients required surgical intervention. Patients who can tolerate mitral valve surgery have a good chance of recovering the voice as a result of the reduction in pulmonary artery pressure as shown in our second case. Early surgical treatment for all symptomatic and asymptomatic aneurysms has been recommended to avoid complications such as thrombosis, rupture, dissection or peripheral embolization. ${ }^{11}$

The treatment of unilateral vocal cord palsies (UVCP) depends on the degree of vocal cord paralysis and whether the opposite, normal side can compensate for this atrophy. Early rehabilitation is essential. It is not necessary to perform any additional surgical procedures on the vocal folds if the patient shows sufficient improvement during speech therapy as shown in our second case. Definitive treatment should be considered if aspiration is severe or if no improvement is visible after alleviation of the cardiac problem, ${ }^{7}$ depending on the patient's need for better vocalization for occupational or social reasons. ${ }^{5}$ Patients with underlying lung disease, a high risk of aspiration or persistent symptoms after one year should also be considered for surgery. Studies have found that UVCP increases the risk of aspiration by impairing various airway protection mechanisms such as laryngeal elevation, epiglottic tilting, closure of both the true and false vocal cords and effective coughing. Previous studies reported that $40 \%$ of patients with UVCP had symptoms of aspiration and $50 \%$ had laryngeal penetration of aspiration.?

Various surgical options are available to medialize the paralyzed vocal cord. The options range from thyroplasty to injection augmentation or injection laryngoplasty.

Cardiovocal syndrome is rare in the general population but associated with causes such as aneurysms and mitral valve stenosis. A high index of suspicion is needed to make an early diagnosis which can lead to surgical correction of the potentially life-threatening, underlying cardiovascular disease. Following such treatment, the cardiovocal syndrome usually resolves spontaneously as vocal cord function returns, often without a need for additional invasive treatment.

\section{REFERENCES}

1. Ortner NI. Recurrenslähmung bei Mitralstenose. [article in German] Wien Klin Wochenschr. 1897;10:753-5.

2. Solanki SV, Yajnik VH. Ortner's syndrome. Indian Heart J. 1972 Jan; 24(1): 43-6.

3. Sengupta A, Dubey SP, Chaudhuri D, Sinha AK, Chakravarti P. Ortner's syndrome revisited. J Laryngol Otol. 1998 Apr; 112: 377-9.

4. Thirlwall AS. Ortner's syndrome: a centenary review of unilateral recurrent laryngeal nerve palsy secondary to cardiothoracic disease. J Laryngol Otol. 1997 Sept;111:869-71.

5. Mulpuru SK, Vasavada BC, Punukollu GK, Patel AG. Cardiovocal syndrome: a systematic review. Heart Lung Cir. 2008 Feb;17(1): 1-4.

6. Phua GC, Eng PC, Lim SL, Chua YL. Beyond Ortners's syndrome-unusual pulmonary complications of the giant left atrium. Ann Acad Med Singapore. 2005 Nov; 34 (10): 642-5.

7. Lee SI, Pyun SB, Jang DH. Dysphagia and hoarseness associated with painless aortic dissection: a rare case of cardiovocal syndrome. Dysphagia. 2006 Apr; 21(2):129-32.

8. Loughran S, Alves C, MacGregor FB. Current aetiology of unilateral vocal fold paralysis in teaching hospital in the West of Scotland. J Laryngol Otol. 2002 Nov; 116(11): 907-10.

9. de Bakey ME, McCollum CH, Graham JM. Surgical treatment of aneuryms of descending thoracic aorta: long-term result in 500 patients. J Cardiovasc Surg (Torino).1978 Nov-Dec;19(6): 571-6.

10. Teixido MT, Leonetti JP. Recurrent laryngeal nerve paralysis associated with thoracic aortic aneurysm.Otolaryngol Head Neck Surg. 1990 Feb;102(2): 140-4.

11. Bower TC, Pairolero PC, Hallett JW Jr, Toomey BJ, Gloviczki P, Cherry KJ Jr. Brachiocephalic aneurysm: the case for early recognition and repair. Ann Vasc Surg.1991 Mar; 5(2): 125-32. 